\title{
Fintech: Digital Tokens
}

\author{
Uma V. Sridharan \\ Columbus State University
}

\author{
V. Sridharan \\ Clemson University
}

\author{
Tobias M. Huning \\ University of North Florida
}

\begin{abstract}
Since the world's first virtual currency was issued on the Bitcoin blockchain network in 2009, there has been a proliferation of various other private digital token offerings on blockchain networks-in particular, on the Ethereum blockchain. Milkau and Bott (2018) report that several governments are considering implementing digital currencies as a "complement to cash." Blockchain technology holds great promise for innovative applications capable of facilitating any number of business operations, and several large companies including IBM, American Express, Toyota, JP Morgan Chase, Goldman Sachs, Walt Disney, Oracle, and Facebook have already invested heavily in the emerging technology. Crowdfunding is also a popular application of blockchain technology. Tech entrepreneurs have issued digital tokens for virtual currency as a means of circumventing the tedious regulations of the SEC governing the raising of capital. The regulatory status of these digital tokens and their associated trading platforms has been approached with a certain degree of ambiguity and controversy. This paper explores and explains the regulatory issues of fintech regarding digital tokens, making a valuable addition to the scarce literature on this topic.
\end{abstract}

Keywords: Blockchain Technology, Fintech, Digital Tokens, Virtual Currency, CFTC, SEC, Bitcoin, Ethereum, DAO

\section{INTRODUCTION}

Blockchain technology refers to the computer technology used to create a digital ledger of economic transactions within a distributed network in a manner that is very difficult, if not impossible, to corrupt (Tapscott and Tapscott, 2016). The computer code used to create the blockchain network is open source code, which allows others to review and improve it. Bitcoin is a virtual currency, or cryptocurrency, which was created in 2009 as an alternative to cash payment, and constitutes the first network created using blockchain technology. In 2015 a blockchain network called Ethereum was created by a Swiss nonprofit organization called the Ethereum Foundation. The cryptocurrency on the Ethereum network is called Ether. Bitcoin and Ether are similar yet different in important ways. Unlike government-issued fiat currencies, the issuance of Bitcoin or Ether is not centrally controlled and both allow payments to be 
made anonymously. While Bitcoin was designed as an alternative digital currency, Ethereum was designed to implement smart contracts, which are computer code that overlays a blockchain with a set of rules that contracting parties agree to. If and when the rules are met, the contract self-executes, eliminating the need for third parties to verify and enforce the transaction. Ethereum, therefore, permits the creation of markets and registries of indebtedness and assets, while eliminating the need for financial intermediaries.

Two terms used in the context of blockchain networks are digital coin and digital token. While these terms are often used interchangeably, they have important differences. Digital coins are digital currency, which serves as an account unit, a medium of exchange, and a value storage tool. Bitcoin (BTC) on the Bitcoin network, Ether (ETH) on the Ethereum Network, Ripple (XRP) on the Ripple network and NXT on the NXT platform are all examples of digital coins. Digital tokens, in contrast, are broader in concept and can represent claims to assets, voting rights, and customer reward points. The Token Alliance, a global organization of 350 blockchain and token experts, define digital tokens as "transferable units generated within a distributed network that tracks ownership of the units through the application of blockchain technology."

\section{INITIAL COIN OFFERINGS (ICOs)}

Since its inception, there has a been a steady evolution of blockchain technology in a number of areas - most notably in the area of crowdfunding, or fundraising via initial coin offerings ( ICOs). Coindesk provides the following data on fundraising via ICO from 2017 through April 2018.

E.: coindesk

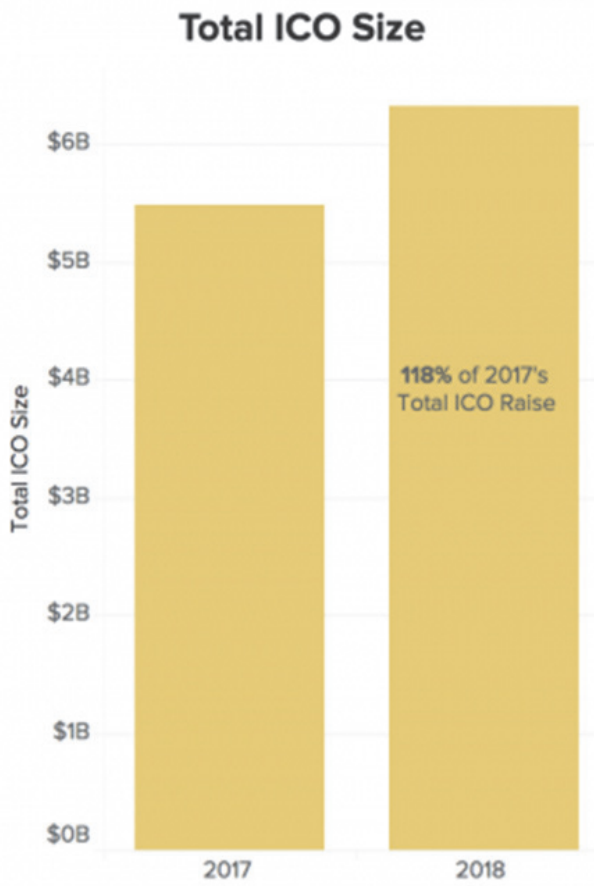

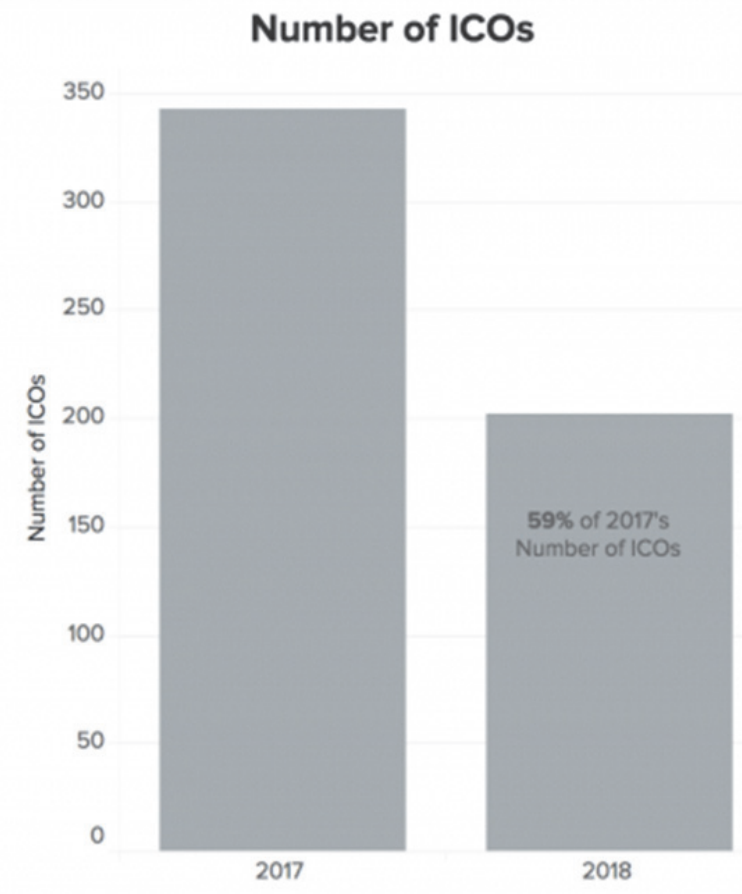

Number of ICOs

Source: https://www.coindesk.com/6-3-billion-2018-ico-funding-already-outpaced-2017

It appears that a number of entrepreneurs, particularly in the area of technology, have chosen to circumvent capital market regulations by raising money from the general public via digital tokens, rather than going through the tedious process of issuing shares and bonds. These entrepreneurs have offered a variety of tokens, including some that are essentially shares in an investment fund and others that can be exchanged for specific end-uses. Each digital token issuer essentially creates its own digital currency 
using the code made publicly available by Ethereum, and the digital currency is sold to the public using Bitcoin or Ether. Purchasers of the ICO electronically transfer the appropriate amount of Bitcoin or Ether from their own digital wallet to the issuer's digital wallet.

\section{THE DAO OFFERING}

In September 2013, Daniel Larimer, a software programmer proposed the idea of a decentralized autonomous organization (DAO). The legal status of DAOs is not clear because such organizations are not domiciled in any particular country. Rather, DAOs exist as computer code that is controlled by its shareholders in cyberspace. Participants can control their identity and personal information in a DAO and, as Russian Canadian prodigy, programmer, and cofounder of Ethereum Vitalik Buterin suggests, after a DAO is launched, it can run independently, without any human interaction, as long as the contracts are "Turing complete." In other words, the code should have the capacity to recognize and/or decide on alternative rule sets for data manipulation. To establish something as Turing complete it must be able to simulate another Turing complete system.

In April-May 2016, Christopher Jentzsch, his brother Simon Jentzsch, and Stephan Tual via their firm, Slock.it UG (a German corporation), created an unincorporated organization along the lines proposed by Larimer and Buterin, which they called "The DAO" (hereafter DAO). Investors in DAO paid approximately twelve million Ether to acquire 1.15 billion DAO digital tokens. At the time the funds were raised DAO had an approximate market value of US\$150 million. DAO tokens gave the holders voting rights on investment proposals and the potential earnings from the projects would offer token holders a return on their investments. The token holders would then vote on whether the returns would be reinvested in new projects or distributed to token holders. The list of projects to be voted on was selected by "curators," who were selected by Slock.it. DAO token holders could resell their DAO tokens in a secondary market and they could also be redeemed for Ether over a period of approximately 46 days.

\section{U.S. SECURITIES REGULATIONS}

The Securities Act of 1933 regulates the distribution of new securities in the U.S.A. The Securities Act of 1934 regulates brokers, exchanges, and trading securities. The Securities Acts of 1933 and 1934 were passed following the U.S. stock market crash of 1929 after many investors lost large amounts of money to unscrupulous promoters. The 1933 and 1934 statues were enacted to protect investors and to require firm promoters to provide investors with sufficient information to allow investors to make informed decisions about investments before committing funds. The 1934 act created the Securities and Exchange Commission (SEC), a federal office that enforces the act of 1933. The statues of 1933 and 1934 require, in general, that all securities offered in the U.S.A. are registered with the Securities and Exchange Commission unless specifically exempted; for example, under Regulation D exemptions. Regulation D stipulates that smaller companies may raise debt and equity capital without registering their securities with the SEC, but they still have to comply with all applicable state laws and must file Form D with the SEC specifying the names and addresses of company executives and directors as well as certain information relevant to the securities issue.

DAO was not registered in the U.S.A. or any other country-DAO simply used the Ethereum platform to offer tokens to investors around the world (including U.S. investors). Since DAO promoters did not comply with U.S. Securities regulations or seek exemption by filing Form D with the SEC, they presumably assumed that DAO tokens did not constitute a security under U.S. securities laws.

\section{THE DAO ATTACK}

The flexibility provided by the Ethereum platform relative to the Bitcoin platform also made it more vulnerable to a hack. In the latter half of May 2016, security concerns were raised about DAO's code. In response, Slock.it appointed a security expert to DAO and planned a freeze on all DAO's investment 
proposals until necessary changes were made to DAO's code to address its vulnerabilities. On June 17, 2016, shortly after DAO's crowdfunding launch, an unidentified hacker (or hackers) began diverting ETH from DAO's digital wallet to an Ethereum blockchain address controlled by the hacker. The hacker successfully moved approximately a third of the total amount of funds raised by DAO. However, DAO's code prevented the hacker from moving the stolen ETH from the wallet it was diverted to for a period of 27 days. During this time Slock.it and its cofounders implemented a fix called "Hard Fork" to the Ethereum blockchain. As a result of this fix, all the funds raised, including those stolen by the hackers, were returned to a DAO recovery address and token holders were given the opportunity to redeem their DAO tokens for Ether without suffering any losses.

The DAO attack exposed the risks and vulnerabilities potentially faced by investors of investment opportunities such as those advertised on digital platforms. The Securities and Exchange Commission conducted an independent investigation on the DAO incident pursuant to Section 21(a) of the Securities Act and published its report on July 25, 2017. In its report the SEC concluded that DAO tokens were, in fact, securities and DAO promoters were required to comply with U.S. securities laws because the securities were offered and sold in the United States. The SEC emphasized that the Securities Acts of 1933 and 1934 applied to the issuing entity of securities regardless of whether

a. the issuing entity is "a traditional company or decentralized autonomous organization,"

b. the securities are paid for in U.S. dollars or virtual currencies, and

c. the securities are distributed in the form of certificates or via blockchain technology.

The SEC ruled that both Sections 5(a) and 5(c) of Securities Act 1933 and 1934 prohibit unregistered offers or sales of securities in interstate commerce and that violations of Section 5 do not require scienter-i.e., intent or knowledge of wrongdoing. While the Supreme Court has held scienter as a requirement of prosecuting insider trading under Sections 10(b) of the Securities Exchange Act and Rule $10 \mathrm{~b}-5$, it is not required for civil action under Section 5.

Citing SEC v. Edwards, 540 U.S. 389, 393 (2004) ; SEC v. W. J Howey Co., 328 U.S. 293, 301 (1946) and United Housing Fund, Inc. vs Forman, 421, U. S. 837,852-53, the SEC ruled that "foundational principles of securities laws applied to virtual organizations or capital raising entities making use of distributed ledger technology." The SEC emphasized that in determining whether a token should be called a security, substance should take precedence over form and the "economic realities underlying a transaction" should be emphasized. The SEC clarified that digital tokens, cash, or anything of value could be construed as a contribution that could create an investment contract. The fact that the digital token holders had a reasonable expectation of profit demonstrated sufficient similarity between digital tokens and securities. Even though DAO was described as a decentralized autonomous organization, the curators of DAO and the cofounders of Slock.it actively oversaw DAO, and the digital tokens derived value from their managerial expertise. The digital token holders had voting rights but they were very limited. This, combined with the anonymity and diffusion of token holders, deprived the token holders of any real control over DAO. So, even though nominal responsibility was seemingly assigned to DAO token holders, in reality, the token holders relied upon the managerial expertise of DAO curators and Slock.it. Citing Steinhardt Group v. Citicorp, 126, F. Ed 144, 152 ( $3^{\text {rd }}$ Cir. 1997) the SEC concluded that the voting rights of DAO token holders were similar to that of a corporate shareholder.

The SEC held that DAO was an unincorporated organization that offered and sold digital tokens in exchange for Ether through the DAO website to persons, including individuals in the U.S.A. Because the digital tokens were in fact securities, DAO was required to register the offer and sale of the tokens unless a registration exemption had been applied for and granted. Furthermore, the SEC held that individuals who participate in the unregistered offer and sale of securities without a valid exemption for registration are violating Section 5 of the Securities Act.

According to the SEC, the digital platforms on which the DAO digital tokens were traded met the definition of an exchange or marketplace for trading securities under the Exchange Act Rule 3b-16(a). Such an exchange must be registered with the national securities exchange under Section 6 of the Exchange Act unless it is exempted from such registration. As such, while the platforms on which the 
digital tokens were sold were not registered, they were not actually exempt from registration. Therefore, the trade of the digital tokens was deemed unlawful under Section 5 of the Exchange Act.

\section{SUMMARY AND CONCLUSION}

The rapid exploitation of blockchain technology and developments in fintech since 2008 have given rise to digital tokens, virtual currencies, trading platforms on distributed ledgers, and many other exciting innovations. These financial and technological innovations are changing the financial landscape at warp speed, such that the law and regulators are sometimes in the position of having to play catch-up to ensure the existence of a free and fair trading system and adequate protection for investors so they can continue to make informed judgments about investments. The law also provides for recovery rights for investors if they can prove that there was inadequate disclosure by the issuers and the issues were not fully compliant with the law. The SEC investigation into the DAO case helped provide much-needed clarification to issuers and investors about what constitutes a security and what the responsibilities of the issuers of such securities are under the law. The current SEC chairman, Jay Clayton, has publicly opined that he views virtual currencies (such as Bitcoin and Ether) as commodities and not securities. However, the SEC has yet to make a formal pronouncement on the subject. The Commodities Futures and Trade Commission (CFTC) has designated Bitcoin as a commodity and the court upheld this view in the matter of Coinflip Inc. d/b/a Derivabit and Francisco Riordan CFTC docket 15-29. Under the Commodities Exchange Act (CEA) the definition of a commodity is very broad and includes all "services and rights and interests . . in which contracts for future delivery are presently or in the future dealt with" with the express exclusion of onions and box office receipts.

The U.S. Internal Revenue Commission has been relatively quick to clarify its position on the tax aspects of digital currencies (IRC, 2014, 2018), but the U.S. Security and Exchange Commission has not clarified its position with as much alacrity. The SEC's official position on whether all digital tokens are securities or whether some could be considered commodities continues to be unclear. However, on Dec 17, 2017, the SEC put out a public statement saying "investors should understand that to date no initial coin offerings has been registered with the SEC. The SEC also has not, to date, approved for listing and trading any exchange-traded products (such as ETFs) holding cryptocurrencies or other assets related to cryptocurrencies. If any person today tells you otherwise, be especially wary." (emphasis in original) The SEC maintains that even though Bitcoin has been designated by the CFTC as a commodity, "products linked to the value of underlying digital assets, including Bitcoin and other cryptocurrencies, may be structured as securities products subject to registration under the Securities Act of 1933 or the Investment Company Act of 1940.” At a February 6, 2018, meeting of the Senate Committee on Banking, Housing and Urban Affairs concerning cryptocurrencies, the SEC chairman stated: "I believe every ICO I've seen is a security." This statement would seem to call into question the legal status of such offerings if they are not registered with the SEC. Meanwhile, the initial coin offerings continue. On May 29, 2018, the SEC brought an emergency court order to stop an ICO for US\$21 million led by Titanium Blockchain Infrastructure Services and its president Michale Allen Stollery. On October 11, 2018, the SEC brought an emergency court order against Blockvest LLC and its founder Reginald Buddy Ringhold III to stop a planned ICO that the promoters had falsely claimed had obtained SEC approval. On November 29, 2018, the SEC settled charges with the well-known boxer Floyd Mayweather Jr. and music producer DJ Khaled for failure to disclose compensation they received for promoting ICOs. In such an uncertain environment, investors in privately issued digital products should tread lightly and with caution, looking to future SEC action and pronouncements to gain more insight into this subject. 


\section{REFERENCES}

Buterin, V. (2013). Bootstrapping a decentralized autonomous organization: Part 1. Retrieved January 6, 2019, from https://bitcoinmagazine.com/articles/ bootstrapping-a-decentralized-autonomouscorporation-part-i-1379644274/

Coinflip Inc. d/b/a Derivabit and Francisco Riordan CFTC docket 15-29. (n.d.). Retrieved from https://www.cftc.gov/sites/default/files/idc/ groups/public/@1renforcementactions/documents/legalpleading/enfcoinfliprorder09172015.pdf

IR-2014-36. (2014). IRS virtual currency guidance: Virtual currency is treated as property for U.S. federal tax purposes; general rules for property transactions apply. Retrieved from https://www.irs.gov/newsroom/irs-virtual-currency-guidance

IR-2018-71. (2018). IRS reminds taxpayers to report virtual currency transactions. Retrieved from https:/www.irs.gov/newsroom/ irs-reminds-taxpayers-to-report-virtual-currency-transactions

Larimer, D. (2013). The hidden cost of Bitcom. Retrieved from https://letstalkbitcoin.com/is-bitcoinoverpaying-for-false-security

Milkau, U., \& Bott, J. (2018). Digital currencies and the concept of money as a social agreement. Journal of Payments Strategy \& Systems, 12(3), 213-231.

SEC v. Edwards, 540 U.S. 389, 393. (2004).

SEC v. W. J Howey Co., 328 U.S. 293, 301. (1946).

Steinhardt Group v. Citicorp, 126, F. Ed 144, 152 ( ${ }^{\text {rd }}$ Cir. 1997)

Tapscott, D., \& Tapscott, A. (2016). Blockchain revolution: How the technology behind Bitcoin is changing money, business and the world. New York, NY: Penguin Random House

Token Alliance. ( 2018). Understanding digital tokens, market overview and proposed guidelines for policymakers and practitioners. Retrieved from https://digitalchamber.org/token-alliancewhitepaper/

United Housing Fund, Inc. vs Forman, 421, U. S. 837,852-53.

US SEC Statement on cryptocurrencies and initial coin offerings. (n.d.). Retrieved from https://www.sec.gov/news/public-statement/statement-clayton-2017-12-11

US SEC Annual Report Division of Enforcement. (n.d.). Retrieved from https://www.sec.gov/files/enforcement-annual-report-2018.pdf 